\title{
IMPLEMENTASI INTERPRETIVE TRANSFORMER APPROACH DALAM MIGRASI DATA SEBAGAI RANGKAIAN DATABASE REENGINEERING
}

\author{
Defa Hanifta Putra, Helmie Arif Wibawa \\ Jurusan Ilmu Komputer/Informatika, Fakultas Sains dan Matematika, Universitas Diponegoro, \\ Jalan Prof. H. Soedarto, SH. Tembalang, Semarang, 50275, Indonesia \\ defahaniftaputra@gmail.com
}

\begin{abstract}
ABSTRAK
Data digunakan pada hampir setiap sistem/aplikasi/software yang mendukung aktivitas suatu organisasi dalam bentuk database.Aktivitas organisasi yang semakin kompleks menyebabkan sistem harus memiliki fitur yang semakin kompleks pula.Pada beberapa kasus, organisasi bahkan perlu mengganti sistem meskipun dengan data yang sama dengan sistem lama. Sistem yang baru memiliki data kosong sehingga perlu data dari sistem lama melalui migrasi data. Migrasi data dilakukan dengan database reengineering yang terdiri dari tiga tahap yaitu translasi skema, konversi data, dan translasi basis data program. Migrasi data yang besar memerlukan metode interpretive transformer approach pada tahap konversi data karena runtutan proses yang relevan. Melalui penerapan rangkaian database reengineering, data dapat dimigrasikan dari sistem lama ke sistem yang baru tanpa harus membangun data dari nol.
\end{abstract}

Kata kunci : data, migrasi data, database reengineering, Prestashop, interpretive transformer approach

\section{PENDAHULUAN}

Data merupakan komponen penting dalam suatu sistem/software/aplikasi. Berbagai organisasi menggunakan sistem yang mendukung aktivitasnya yang mana di dalamnya terintegrasi data yang terbungkus dalam basis data.Aktivitas organisasi yang semakin kompleks menuntut organisasi tersebut memiliki sistem dengan fitur (fungsi) yang semakin kompleks pula. Sistem yang mendapatkan update fitur dukungan sangat relevan untuk terus dipakai.

Namun ada beberapa organisasi/perusahaan yang harus mengganti sistem karena pertimbangan dukungan fitur. Dalam hal ini penelitian dilakukan terhadap sebuah website yang memiliki domain www.edusarana.com. Website ini dibangun dengan CMS berbasis Zen Cart, setelah dilakukan analisis, ternyata dukungan fitur Prestashop lebih dikembangkan daripada Zen Cart. Oleh karena itu perlu dilakukan penggantian sistem dari Zen Cart ke Prestashop dimana analisis dilakukan dalam hal dukungan modul, data, dan antarmuka.

Prestashop sebagai sistem yang baru, memiliki data yang masih kosong. Pembuatan data dari nol pada sistem yang baru memerlukan biaya (harga, sumber daya, waktu) yang sangat mahal. Oleh karena itu diperlukan database reengineering dimana digunakan metode interpretive transformer approach pada tahap konversi data untuk memigrasikan data dalam jumlah besar.

Artikel ini menguraikan tentang proses migrasi data massal dari Zen Cart ke Prestashop dengan mengimplementasikan metode interpretive transformer approach pada tahap konversi data sebagai rangkaian proses database reengineering.

\section{TINJAUAN PUSTAKA}

Data adalah kumpulan diskrit, fakta obyektif tentang suatu peristiwa [2]. Data digunakan pada hampir semua sistem/aplikasi/software yang terbungkus dalam suatu basis data. Basis data adalah suatu koleksi data yang saling berhubungan secara logis dan menggambarkan integrasi antara suatu tabel dengan tabel lainnya, basis data dirancang untuk memenuhi kebutuhan informasi dari suatu organisasi [4]. Suatu CMS (Content Management System) memerlukan basis data 
untuk melakukan operasi fungsionalnya sekaligus sebagai tempat penyimpanan data. Salah satu CMS tersebut adalah Zen Cart dan Prestashop.

Pada suatu kondisi tertentu, suatu organisasi perlu melakukan penggantian sistem sehingga memerlukan migrasi data dari sistem yang lama ke sistem yang baru. Secara umum, migrasi data merupakan aktivitas dimana data dimigrasikan dari platform yang lama ke platform yang baru [1].

Suatu sistem/aplikasi/software cenderung mengalami pembaruan seiring dengan semakin kompleksnya tuntutan fungsi sistem. Hal tersebut tentu melibatkan rekayasa ulang sistem maupun database reengineering dimana komponen sistem yang lama dipergunakan kembali untuk mengembangkan sistem yang baru. Database reengineering adalah merekayasa kembali basis datayang sudah ada dengan harapan sistem yang baru dapat menggunakan basis datalama tanpa harus membuat data dari nol. Database reengineering terdiri dari tiga bagian, yaitu translasi skema (schema translation), konversi data (data conversion), dan translasi database program (database program translation) [3].

Translasi skema merupakan proses awal dalam database reengineering. Translasi skema terdiri dari dua pendekatan utama, yaitu :

\section{a. Direct translation}

Pendekatan ini merupakan pendekatan yang dapat secara langsung menranslasikan skema nonrelasional ke skema relasional. Namun, dengan direct translation sangat rawan terjadi kehilangan informasi karena prinsip direct translation yang mana operasinya cenderung primitif dan tidak dapat me-recovery atau bahkan mengidentifikasi semua skema awalnya yang asli. Indirect translation masih terbagi lagi menjadi beberapa metode, yaitu Direct Translating a Network Model to a Relational Model dan Direct Translating a Hierarchical Model to a Relational Model [3].

\section{b. Indirect translation}

Pendekatan ini merupakan pendekatan yang dilakukan secara berantai. Artinya skema baru didapat dari hasil pemetaan skema yang lama. Metode ini sangat sesuai dengan kasus dalam migrasi data. Oleh karena itu translasi skema yang digunakan adalah dengan indirect translation yaitu melalui pemetaan skema relasi (relational schema) ke model EER (Extended Relationship Model) agar data menjadi lebih mudah dianalisis.

Translasi skema yang menggunakan model relasi memiliki beberapa aturan antara lain:

a. Relasi primer, untuk mendeskripsikan entitas [3].

b. Relasi primer tipe $1\left(\mathrm{PR}_{1}\right)$, relasi ini tidak memiliki kunci primer dari entitas/relasi lain [3].

c. Relasi primer tipe $2\left(\mathrm{PR}_{2}\right)$, relasi ini terdapat entitas/relasi yang berisi kunci primer dari entitas/relasi lain [3].

d. Relasi sekunder, entitas memiliki kunci primer yang secara penuh atau hanya sebagian yang dibangun dari penggabungan dari kunci primer-kunci primer relasi/entitas lainnya [3].

e. Relasi sekunder tipe $1\left(\mathrm{SR}_{1}\right)$, terjadi bila secara keseluruhan dibentuk dari penggabungan kunci primer dari relasi primer [3].

f. Relasi sekunder tipe $2\left(\mathrm{SR}_{2}\right)$, yaitu relasi sekunder yang bukan tipe 1 [3].

g. Key Atribute - Primary (KAP), yaitu atribut pada kunci primer relasi sekunder yang juga merupakan kunci pada beberapa relasi primer [3].

h. Key Atribute - General (KAG), yaitu semua atribut kunci primer lain pada relasi sekunder yang bukan merupakan tipe KAP [3].

i. Foreign key atribute (NKA), yaitu atribut kunci bukan primer dari relasi primer yang merupakan kunci tamu [3].

Dalam hal ini, translasi skema dilakukan dengan memetakan skema relasi basis data ke dalam model Extended Entity Relationship (EER). EER merupakan suatu metode untuk mendefinisikan struktur dan fungsionalitas dari suatu basis dataatau sistem informasi [5]. Secara umum EER diilustasikan pada Gambar 1. 


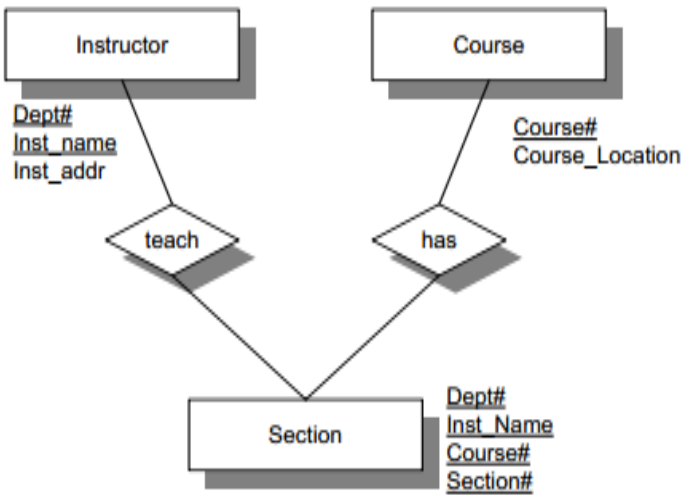

Gambar 1. Model EER [3]

Konversi data merupakan teknik pengubahan database dari sistem lama agar dapat digunakan di sistem yang baru. Konversi data yang baik mampu mengonversi datasource dengan tanpa menghilangkan informasi, artinya tidak ada data penting yang hilang[3]. Konversi data dapat dilakukan dengan berbagai metode, antara lain :
a. Customized Program Approach
b. Interpretive Transformer Approach
c. Translator Generator Approach
d. Logical Level Translation Approach

Interpretive transformer approach merupakan metode dalam konversi data dimana pendekatan ini menerima definisi datasource, definisi data target, memetakan definisi,dan memetakan data dari datasource ke basis data target [3].Interpretive transformer approach memiliki model yang diilustrasikan pada Gambar 2 dan 3 .

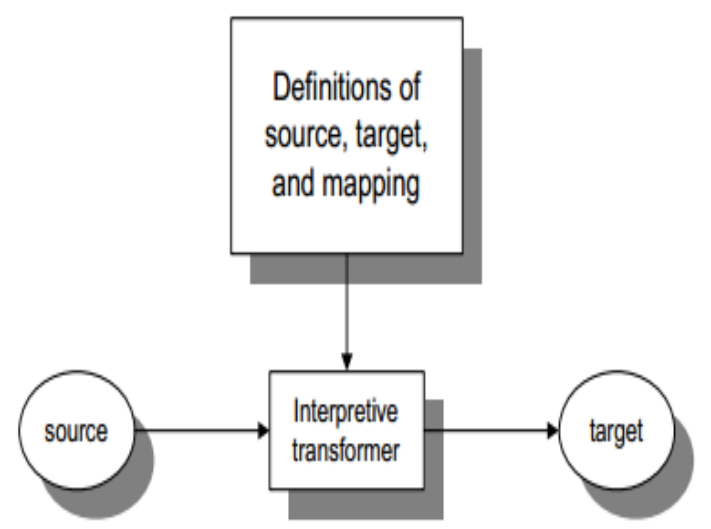

Gambar 2. Interpretive transformer [3]

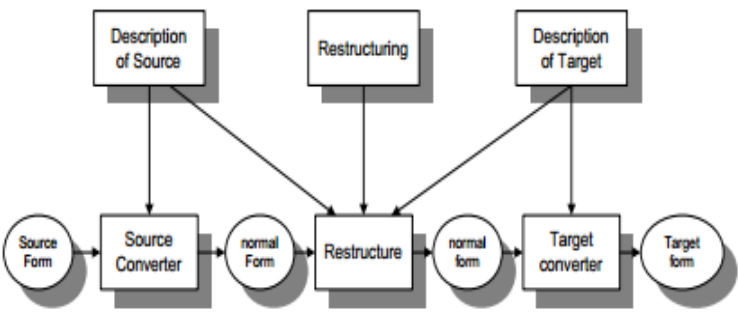

Gambar 3. Model umum generator translator [3]

Interpretive transformer approach memiliki tahap dalam melakukan konversi data seperti diilustrasikan pada Gambar 3 maka sangat relevan untuk diterapkan pada data yang berjumlah ribuan sampai dengan puluhan ribu.

Tahap terakhir dalam database reengineering adalah translasi basis data program. Translasi basis data program merupakan proses menranslasi/menransfer basis data eksternal agar dapat diterima dan digunakan oleh sistem target. Translasi basis data program memiliki 5 pendekatan yaitu:
a. rewriting
b. software interface
c. emulation
d. decompilation
e. co-existence

Emulation merupakan salah satu metode dalam translasi basis data program dimana pendekatan ini melibatkan dukungan software atau firmware pada sistem target yang dapat memetakan commands dari program/sistem sumber ke program/sistem target sehingga ekuivalen [3].

\section{HASIL DAN PEMBAHASAN}

Database reengineering terdiri dari tiga bagian, yaitu translasi skema (schema translation), konversi data (data conversion), dan translasi database program (database program translation).

\section{Translasi Skema}

a. Translasi skema basis data sumber

Translasi skema dilakukan terhadap tabel pembangun kategori dan produk. Skema relasi kategori dan produk dipetakan ke model EER. Skema relasi kategori diilustrasikan pada Skema 1 sedangkan skema relasi produk 
diilustrasikan pada Skema 2. Translasi Skema 1 diilustrasikan pada Gambar 4, translasi Skema 2 diilustrasikan pada Gambar 5.

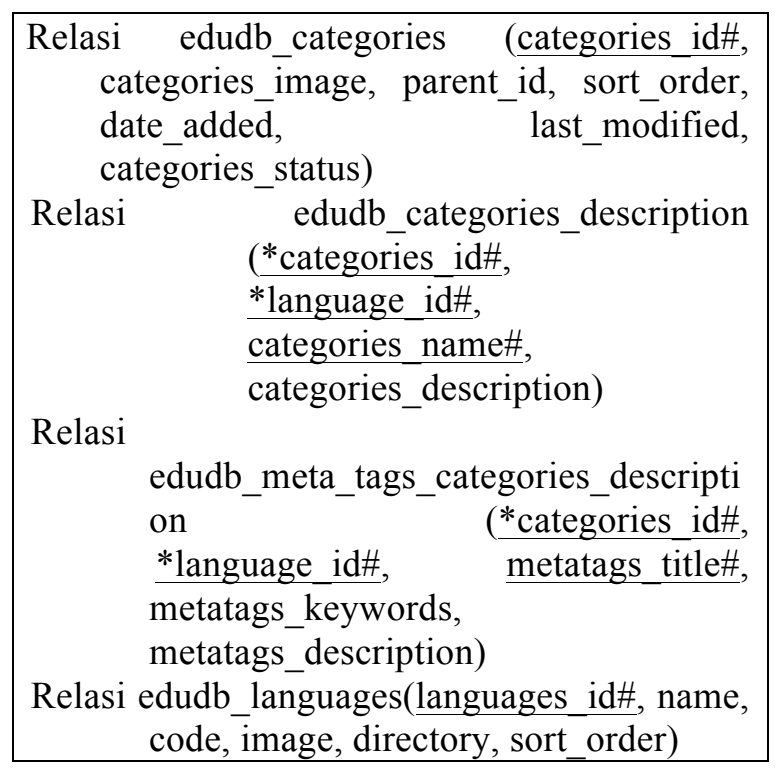
Skema 1. Skema relasi kategori

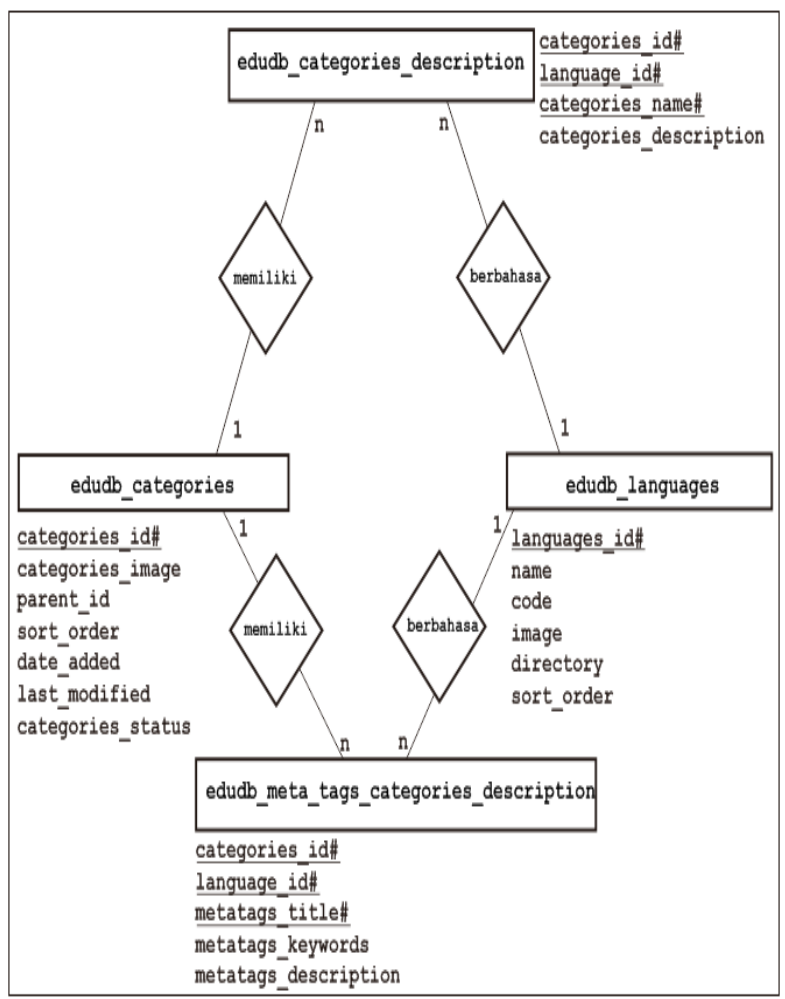

Gambar 4. Model EER kategori

\begin{tabular}{|c|c|}
\hline \multicolumn{2}{|c|}{ 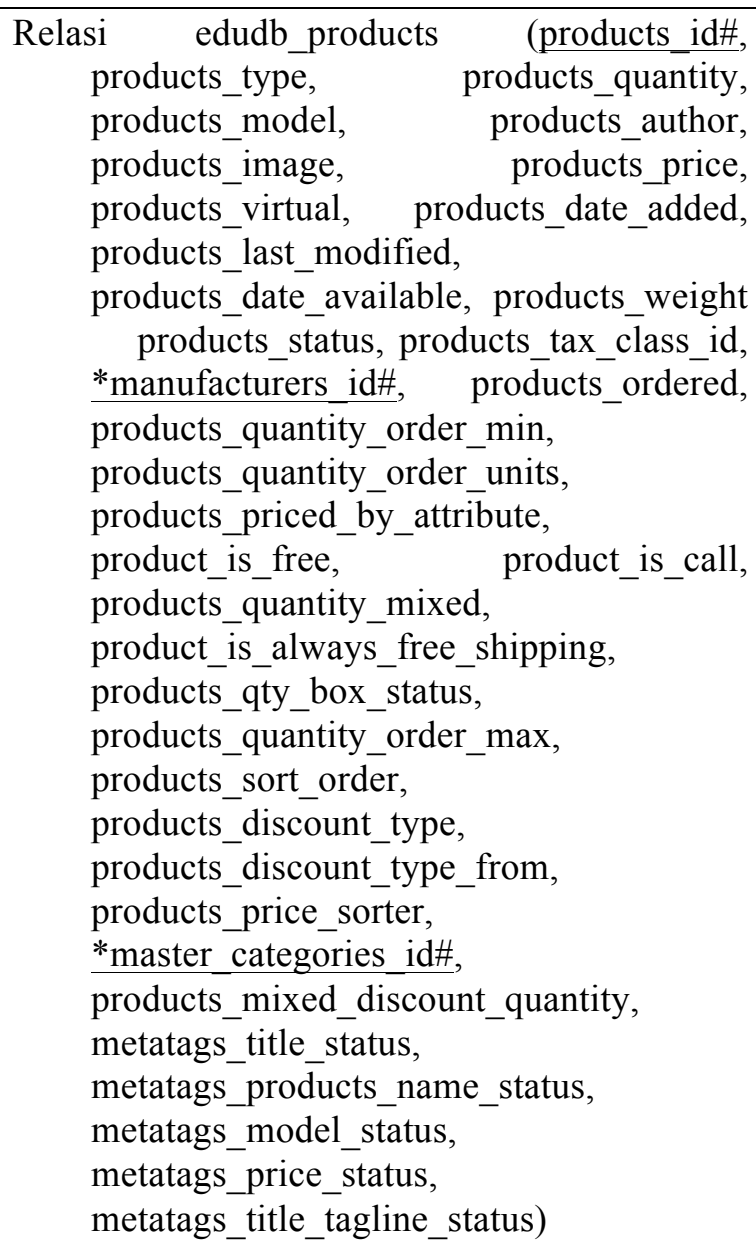 } \\
\hline Relasi & $\begin{array}{l}\text { edudb_products_description } \\
\text { (*products id\#, } \\
\text { products_name, products_description, } \\
\text { products_url, products_viewed) }\end{array}$ \\
\hline Relasi & $\begin{array}{l}\text { (manufacturersid } \mathrm{edud}, \overline{\mathrm{db}} \text { _manufacturers } \\
\text { manufacturers_name, } \\
\text { manufacturers_image, date_added, } \\
\text { last_modified) }\end{array}$ \\
\hline Relasi & $\begin{array}{l}\text { edudb_categories } \\
\text { categories_image, } \\
\text { sort_order, date_added, last_modified, } \\
\text { categories_status) }\end{array}$ \\
\hline Relasi & $\begin{array}{l}\text { *categories id } \#, \quad \text { *language id\#, } \\
\text { categories_name, } \\
\text { categories_description) }\end{array}$ \\
\hline & $\begin{array}{l}\text { i edudb_languages (languages_id\#, name, } \\
\text { code, image, directory, sort_order) }\end{array}$ \\
\hline
\end{tabular}




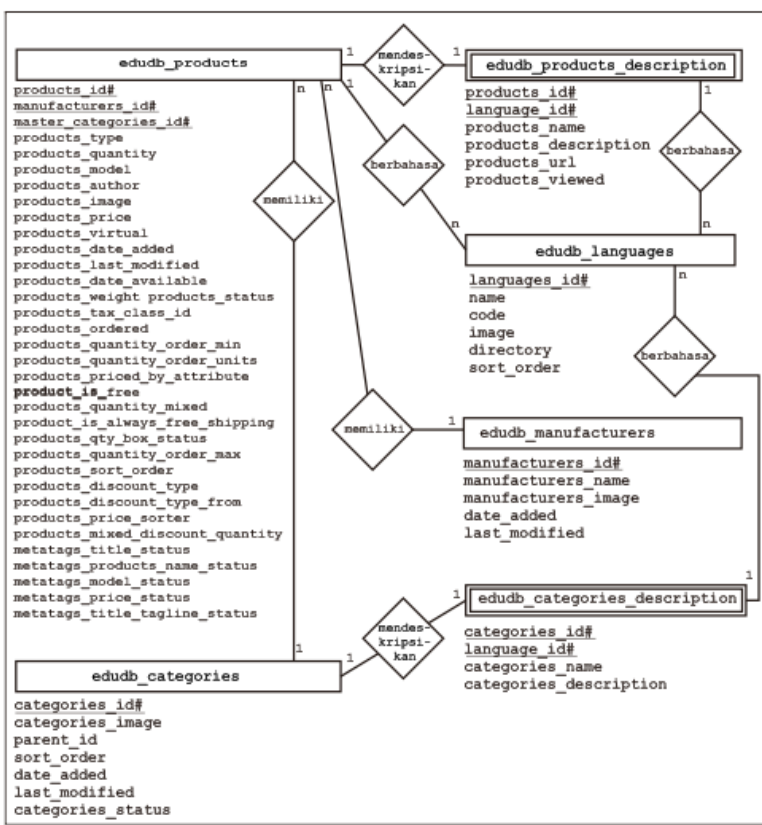

Gambar 5. Model EER produk

b. Translasi skema basis data target

Translasi skema dilakukan terhadap tabel pembangun kategori dan produk. Skema relasi kategori dan produk dipetakan ke model EER. Skema relasi kategori diilustrasikan pada Skema 3 sedangkan skema relasi produk diilustrasikan pada Skema 4. Translasi Skema 3 diilustrasikan pada Gambar 6, translasi Skema 4 diilustrasikan pada Gambar 7.

\begin{tabular}{|c|c|}
\hline Relasi & $\begin{array}{l}\text { edusa_category } \begin{array}{c}\text { (id_category\#, } \\
\text { id_parent, } * \text { id shop default }\end{array} \\
\text { level_depth, nleft, nright, active, } \\
\text { date_add, date_upd, position, } \\
\text { is root category) }\end{array}$ \\
\hline Relasi & $\begin{array}{l}\text { edusa_category_lang }(* \text { id category\#, } \\
\text { *id shop\#, *id lang\#, name, } \\
\text { description, } \\
\text { meta link_ritle, } \\
\text { meta description) }\end{array}$ \\
\hline Relasi & $\begin{array}{l}\text { edusa_lang (id lang\#, name, active, } \\
\text { iso_code, } \\
\text { language_code, } \\
\text { date_format_lite, date_format_full, } \\
\text { is_rtl) }\end{array}$ \\
\hline Relasi & 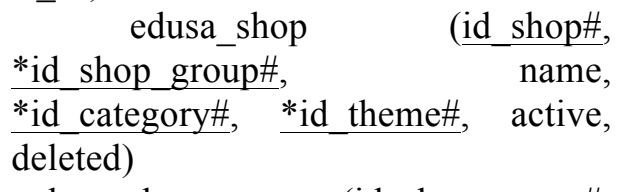 \\
\hline Relasi & edusa \\
\hline
\end{tabular}

name, share_customer, share_order, share_stock, active, deleted)

Relasi edusa_theme (id theme\#, name, directory)

\section{Skema 3. Skema relasi kategori}

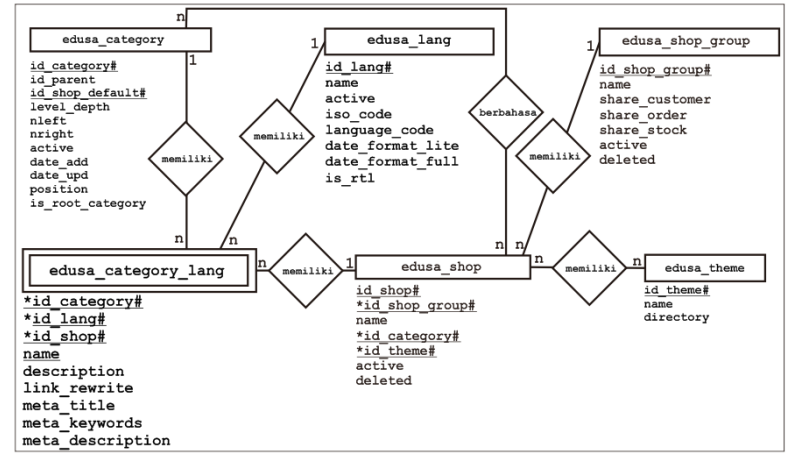

Gambar 6. Model EER kategori

Relasi edusa_product (id_product\#, *id supplier\#, $\quad$ *id manufacturer\#, *id category default\#, *id shop default\#, *id tax rules group\#, on_sale, online_only, ean13, upc, ecotax, quantity, minimal_quantity, price, wholesale_price, unity, unit_price_ratio, additional_shipping_cost, reference, supplier_reference, location, width, height, depth, weight, out_of_stock, quantity_discount, customizable, uploadable_files, text_fields, active, redirect_type, id_product_redirected, available_for_order, available_date, condition, show_price, indexed, visibility, cache_is_pack, cache_has_attachments, is_virtual, cache_default_attribute, date_add, date_upd, advanced_stock_management)

Relasi edusa_category (id category\#, id_parent, $\quad *$ id shop default\#, level_depth, nleft, nright, active, date_add, date_upd, position, is_root_category)

Relasi edusa_product_lang(*id product\#, *id shop\#, *id lang\#, description, description_short, link_rewrite, meta_description, meta_keywords, meta_title, name, available_now, available_later)

Relasi edusa_lang (id lang\#, name, active, iso code, 


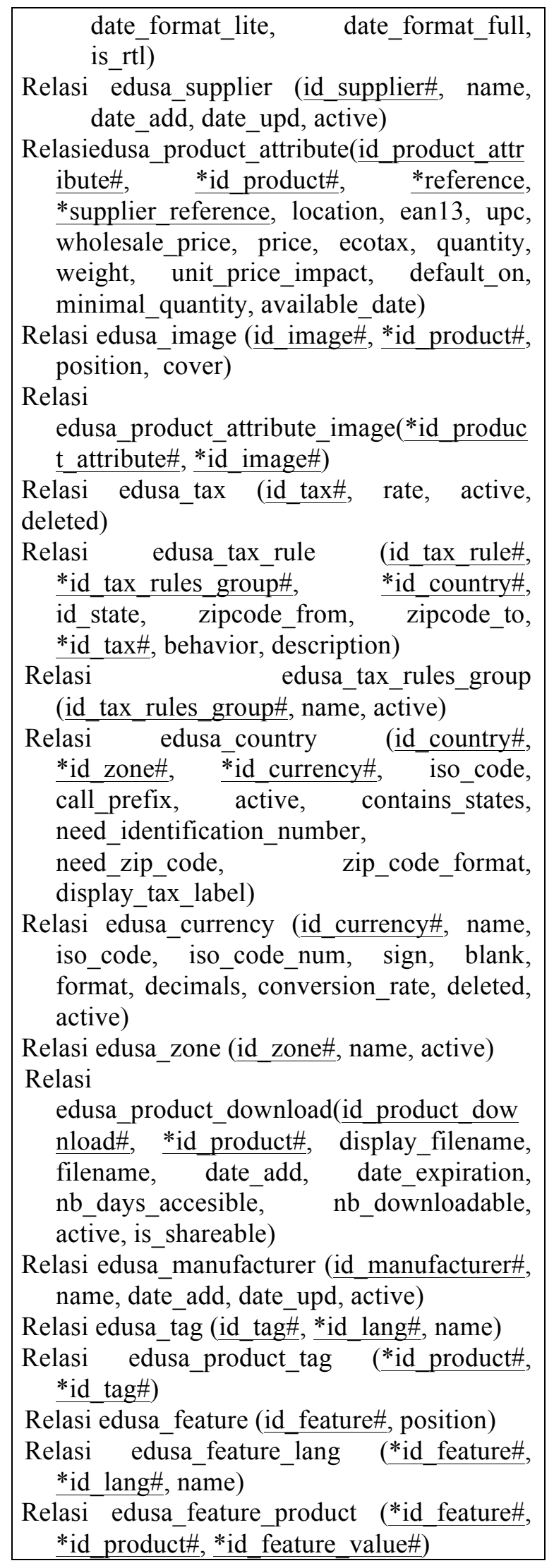

Relasi edusa_feature_value

(id feature value\#, ${ }^{*}$ id feature\#, custom)

Relasi edusa_product_shop(*id product\#, *id shop\#, $\quad \overline{\text { id_category_default, }}$ id_tax_rules_group, on_sale, online_only, ecotax, minimal_quantity, *price, *wholesale price, unity, unit_price_ratio, additional_shipping_cost, customizable, uploadable_files, text_fields, active, redirect_type, id_product_redirected, available_for_order, available_date, condition, show_price, indexed, visibility, cache_default_attribute,

advanced_stock_management, date_add, date_upd)

Relasi

edusa_product_supplier(id product suppl ier\#, $\quad$ *id product\#,

*id product attribute\#, *id supplier\#, product_supplier_reference,

product_supplier_price_te,

*id currency\#)

Relasi edusa_shop (id_shop\#, *id shop group\#, name, *id category\#, *id theme\#, active, deleted)

Relasi edusa_shop_group (id_shop_group\#, name, share_customer, share_order, share_stock, active, deleted)

Relasi edusa_theme (id theme\#, name, directory)

Skema 4. Skema relasi produk 
Implementasi Interpretive Transformer Approach...

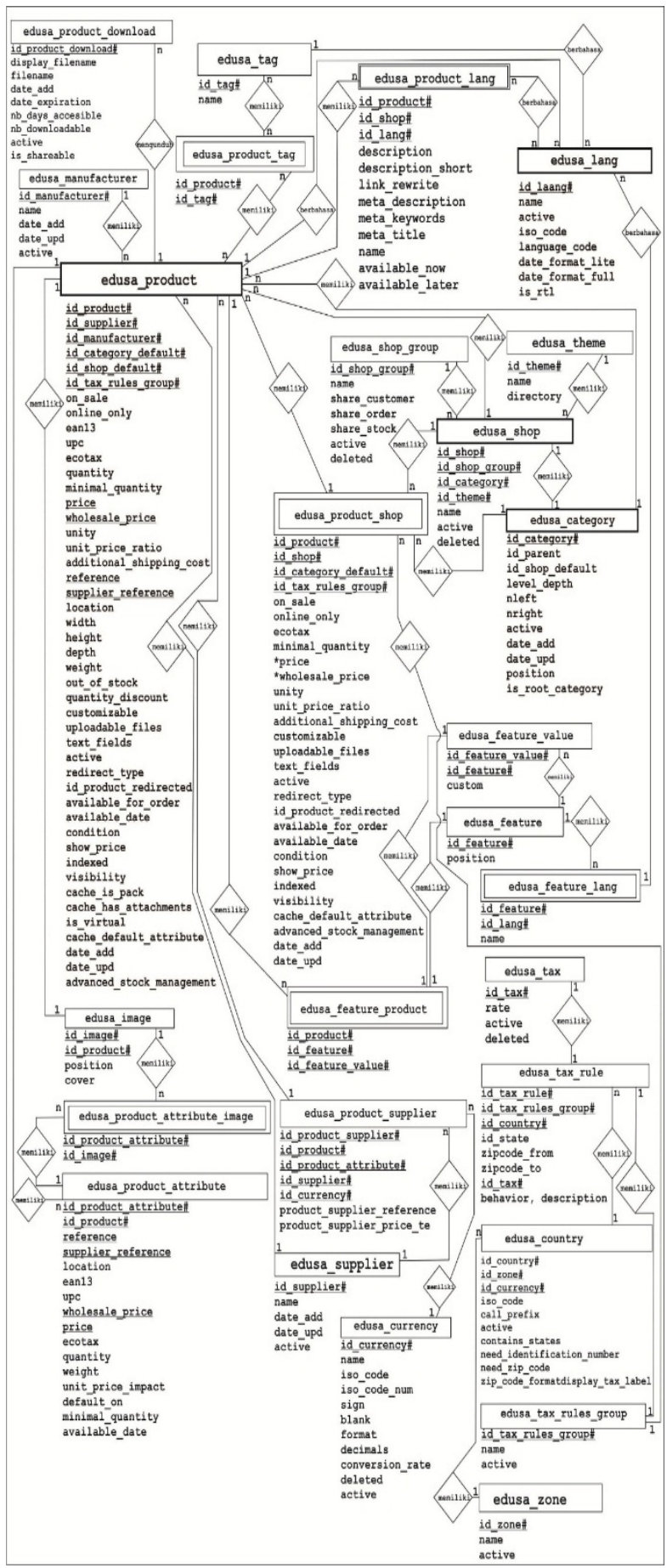

Gambar 7. Model EER produk

\section{Konversi Data}

Konversi data dilakukan dengan menggunakan metode interpretive transformer approach. Proses awal dalam metode ini adalah source converter dimana dalam penelitian ini digunakan
SQL Query untuk mengekstraksi data sumber. Hasil dari proses ini adalah normal formpertama yang diilustrasikan pada Gambar 8 dan Gambar 9.

\begin{tabular}{|c|c|c|c|c|c|c|c|}
\hline id active name & parent categooy & & y description & meta_ itile & e meta keywor & & meta_descipition \\
\hline 1 GUKUKEIARPAKET & BUUU PENODDKAN LUAR SEKOLLH & 0 & & & $\begin{array}{l}\text { LKS, Kegar } \\
\text { Pakele,Les }\end{array}$ & & \\
\hline 1 BUKUKE.AR PAKET & BUKU PENIDDKANI LUAR SEKOLHH & 0 & & & $\begin{array}{l}\text { LKSSKejar } \\
\text { Palket Les }\end{array}$ & & \\
\hline 1 EBOOKSD & E-BDok & 0 & & NULL & & NULL & NULL \\
\hline 1 EBOOK SMP & EBDOK & 0 & & NULL & & NULL & NOLL \\
\hline 1 EBDOK SIMA & E-B00K & 0 & & NUL & & NULL & NULL \\
\hline 1 EBOOK SMIK & E-Book & 0 & & NULL & & NULL & NOL \\
\hline 1 BAHASA & E-B00K & 0 & & NOLL & & NULL & NULL \\
\hline $\begin{array}{l}1 \text { BUKU BANUUAN OPERASONALL } \\
\text { SEKOLLH }\end{array}$ & BUKU BOS DAN DAK & 0 & $\begin{array}{l}\text { BUKU } \\
\text { SEKOLAH }\end{array}$ & NULL & & NULL & NUL \\
\hline 1 BUKU Bos So & $\begin{array}{l}\text { BUKU BANTUAN OPERASIONAL } \\
\text { SEKOLAH }\end{array}$ & 0 & & NULL & & NULL & NUL \\
\hline 1 BUKU BOS SWP & $\begin{array}{l}\text { BUKU BANUIAN OPERASONAL } \\
\text { SEKOLAH }\end{array}$ & 0 & & NULL & & NULL & NUL \\
\hline 1 BUKU DANA ALOKASI KHUSUS & BUKU BOS DAN DAK & 0 & $\begin{array}{l}\text { BUKU } \\
\text { SEKOLAH }\end{array}$ & NULL & & NULL & NOLL \\
\hline 180 & CODVDEBOOKOKNASS & 0 & & NOLL & & NULL & NOL \\
\hline 1 SMP & CDDVVDEBDOOKDKNASS & 0 & & NULL & & NULL & NULL \\
\hline 1 SMAR & CODVD E.BOKK DKNASS & 0 & & NULL & & NULL & NOLL \\
\hline 1 SWK & CODVDE.BOOK OKNASS & 0 & & NULL & & NULL & NULL \\
\hline 1 BUKU HONEKKS PEAARPAN & BUWU PEVIDOKFAN LUAR SEKOLLH & 0 & & NUL & & NULL & NuL \\
\hline 1 BUKU SD & BUKWUBLINGOULL & 0 & & NULL & & NULL & NULL \\
\hline 1 BAHASA & BUKU PERGUUUAU TNGGI & 0 & & NULL & & NULL & NOLL \\
\hline 1 EKONOMI & BUKU PERGUUUAN TNGGI & 0 & & NULL & & NULL & NULL \\
\hline
\end{tabular}

Gambar 8. Normal form pertama hasil source converter dengan SQL Query kategori

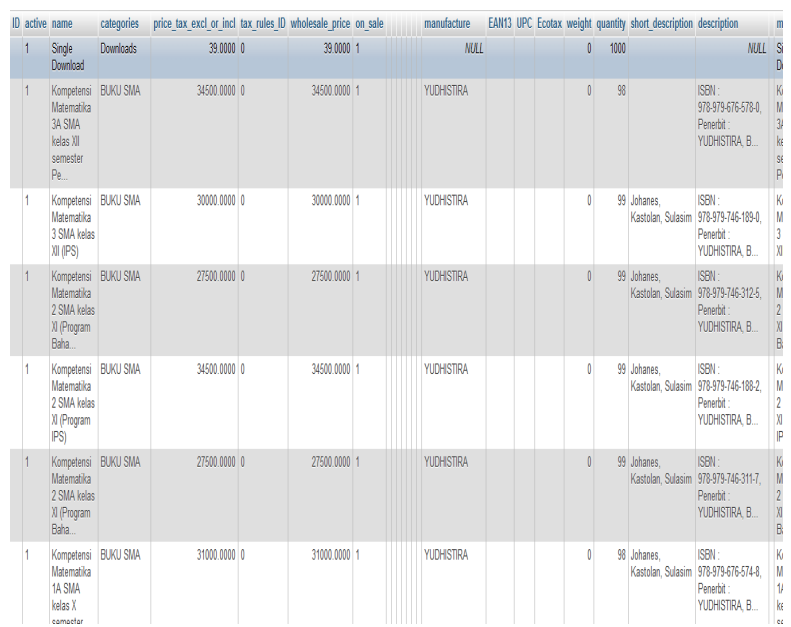

Gambar 9. Normal form pertama hasil source converter dengan SQL Query produk

Normal form pertama disimpan dalam format .csv untuk direstrukturisasi demi menghasilkan normal form kedua. Restrukturisasi dilakukan dengan menghilangkan noise atas data yang didapat. Selain itu restrukturisasi juga untuk menyesuaikan format migrasi csv pada Prestashop. Tabel normal form kedua diilustrasikan pada Gambar 10 dan Gambar 11. 


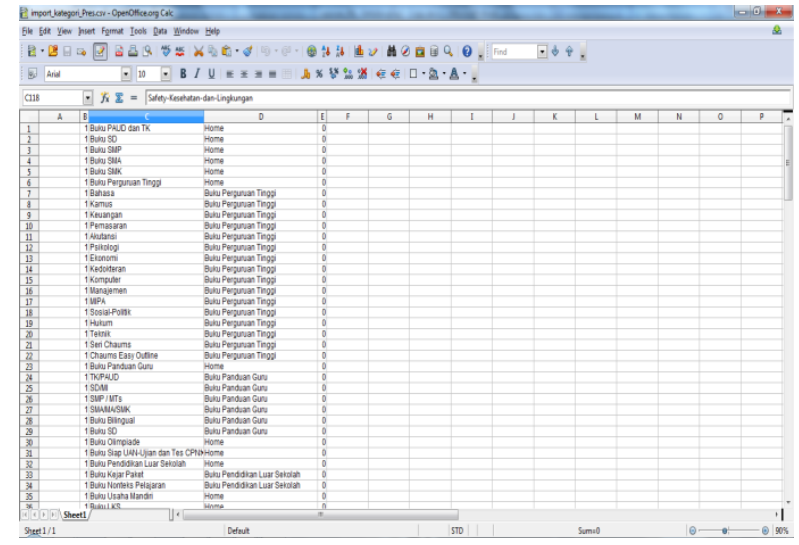

Gambar 10. Tabel normal form kedua kategori

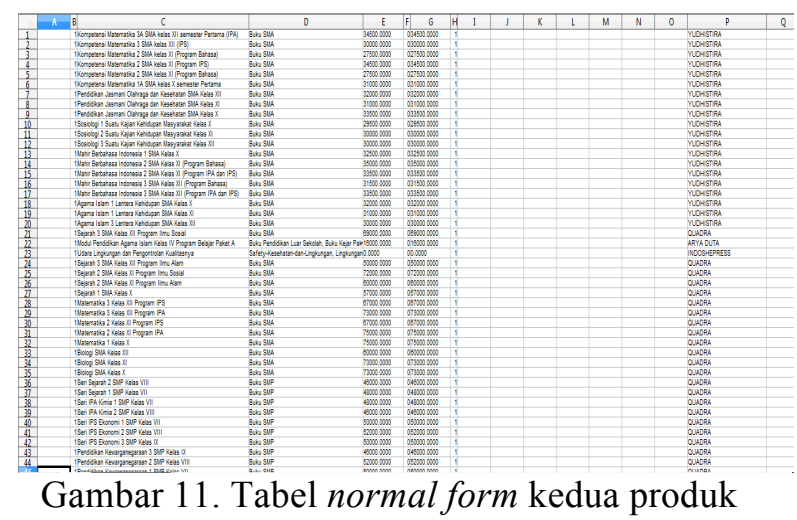

\section{Translasi Basis Data Program}

Translasi basis data program merupakan langkah terakhir dalam database reengineeringdimana data dimigrasikan/dipetakan ke sistem target. Metode yang digunakan ada emulation karena memanfaatkan fitur import yang telah disediakan oleh Prestashop. Artinya migrasi data massal kategori dan produk dilakukan dalam sistem Prestashop melalui fitur import sebagai emulator-nya. Proses ini diilustrasikan pada Gambar 12 dan Gambar 13.

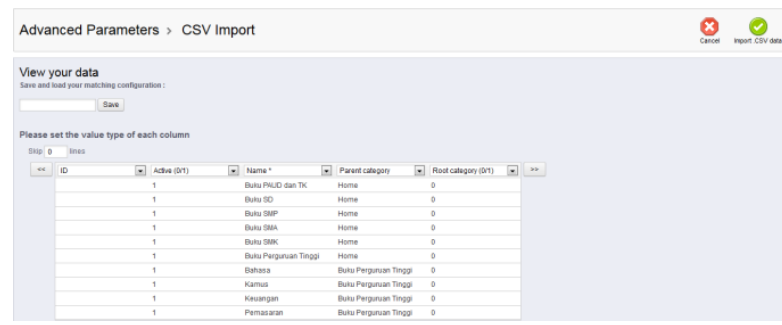

Gambar 12.Emulation dengan fitur import kategori Prestashop

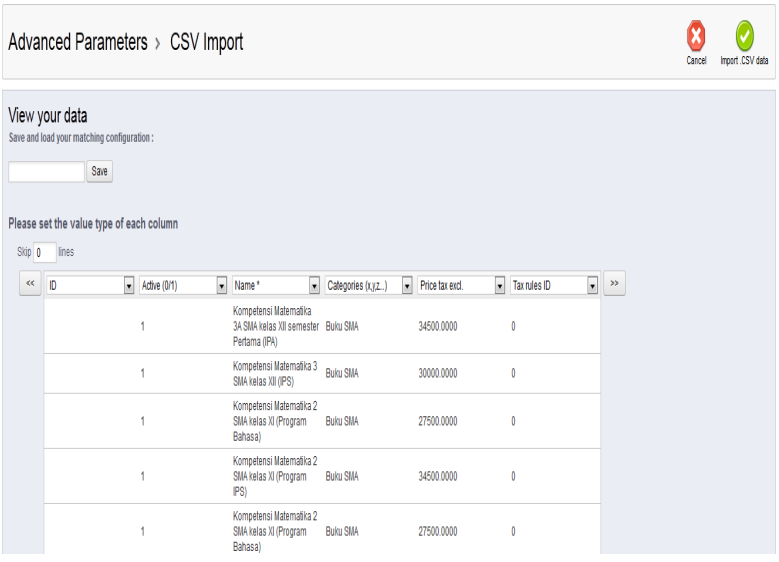

Gambar 13. Emulation dengan fitur import produk Prestashop

Penerapan emulation melalui fitur import memungkinkan data dapat dimigrasikan secara massal. Hasil migrasi data diilustrasikan pada Gambar 14 dan Gambar 15.

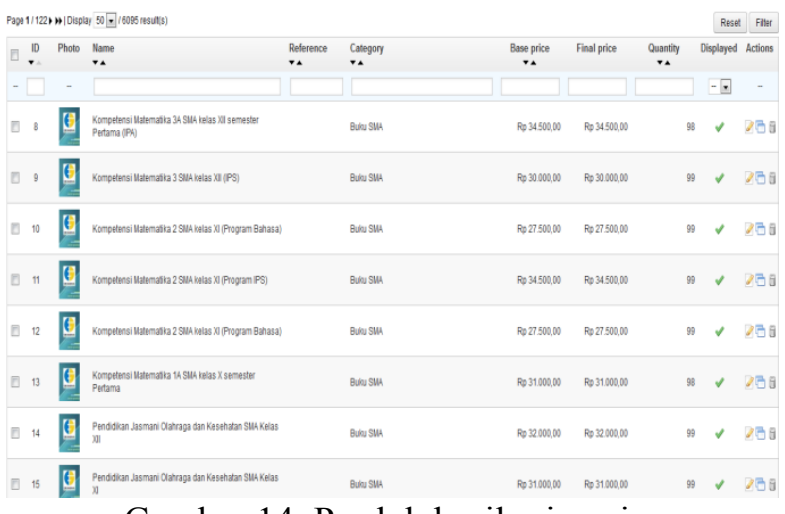

Gambar 14. Produk hasil migrasi

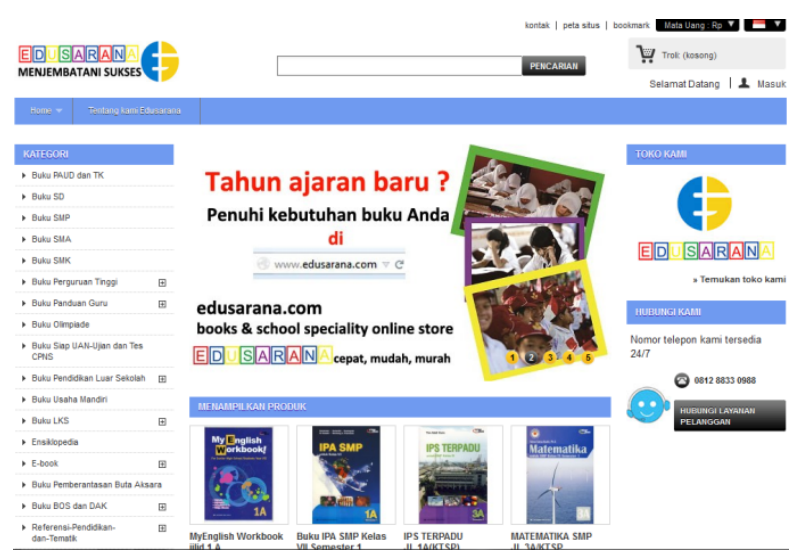

Gambar 14. Website berbasis Prestashop dengan data hasil migrasi 


\section{KESIMPULAN}

Setelah penelitian dilaksanakan, diambil kesimpulan mengenai implementasi interpretive transformer approach dalam migrasi data sebagai rangkaian database reengineering antara lain :

1. Database reengineering perlu diterapkan untuk melakukan migrasi data.

2. Interpretive transformer approach merupakan metode yang relevan untuk konversi data dalam kaus data yang jumlahnya besar (ribuan-puluhan ribu).

3. Data dapat dimigrasikan secara massal dari sistem satu ke sistem yang lain, dalam hal ini dari Zen Cart ke Prestashop.

\section{DAFTAR PUSTAKA}

[1] Ahmadi, R., B.R. Cami dan H. Hassanpour, 2012, “Automatic Data Migration between Two Databases with Different Structure”, International Journal of Applied Information Systems (IJAIS), Volume 3, No.3 : 23.

[2] Davenport, T. H. dan L. Prusak, 2005, "Working Knowledge: How Organizations Manage What They Know", Ubiquity : Ubiquity.

[3] Fong, Joseph. 2006. "Information Systems Reengineering and Integration". Springer : USA.

[4] Robby, O.K. dan Wardana, F.M..(2009)."Analisis dan Perancangan Basis Data untuk Mendukung Aplikasi ERP Education pada Bina Nusantara University (Study Kasus : Academic Management and Content Preparation)". http://ict.binus.edu/metamorph/file/researc h/JournalDBERP.pdf (diakses tanggal 19 Mei 2013).

[5] Thalheim, Bernhard.TT."Extended EntityRelationship Model".Christian-Albrechts University Kiel : Jerman. 